\title{
Fatalities Among Iranian High-altitude Outdoor Enthusiasts: Causes and Mechanisms
}

\author{
Ramin Kordi ${ }^{1}$, MD, MSc, PhD; Mohsen Rostami ${ }^{* 1}$, MD; Pedram Heidari ${ }^{2}$, MD;
} Sanaz Ameli ${ }^{3}$, MD; Lotfali Foroughifard ${ }^{1}$, MD; Mahboobeh Kordi ${ }^{* 1}$, MSc

\author{
Authors' Affiliation: \\ 1. Sports Medicine Research Center, \\ Tehran University of Medical \\ Sciences, Tehran, Iran \\ 2. Center for Translational Nuclear \\ Medicine and Molecular Imaging, \\ Department of Radiology, \\ Massachusetts General Hospital, \\ Harvard Medical School, Boston, \\ USA \\ 3. Noorafshar Rehabilitation \& Sports \\ Medicine Hospital, Tehran, Iran \\ * Corresponding Author; \\ Address: Sport Medicine Research \\ Center, No 7, Al-e-Ahmad Highway, \\ Tehran, P.O Box: 14395-578, IR Iran \\ E-mail: mahboobeh.kordi@gmail.com
}

Received: Apr 16, 2012

Accepted: Sep 16, 2012

Key Words: Mortality; Altitude; Mountaineering; Risk Factors

\begin{abstract}
Purpose: This study was performed to determine the possible causes and mechanisms of fatalities among Iranian mountaineers during climbing.

Methods: By contacting several sources, deceased mountaineers were identified. Data about the causes and mechanism of death was retrospectively obtained using a standard questionnaire for each case.
\end{abstract}

Results: A total of 29 deaths were identified from March 2006 to June 2010. Deceased subjects had a mean age of 39 years (SD: 12.8, Range: 20-67). Falling was the most common accident leading to death of outdoor enthusiasts $(n=14$, $48 \%$ ). Asphyxia $(n=6,24 \%)$ was the most common cause of death among the subjects, followed by heart attack, internal bleeding, cerebral hemorrhage and hypothermia $(17 \%, 17 \%, 17 \%$ and $10 \%$, respectively).

Conclusions: Our findings suggest that education of medical service providers of the climbing groups on facing victims in high altitude areas, where they have limited resources, can be particularly helpful. In addition, a national program to educate mountaineers might help to reduce fatalities.

Asian Journal of Sports Medicine, Volume 3 (Number 4), December 2012, Pages: 285-290

\section{INTRODUCTION}

$\mathrm{H}$ igh altitude activities such as mountaineering and climbing are popular ${ }^{[1]}$ but hazardous ${ }^{[2-4]}$. Considering the growing popularity of mountaineering, increasing numbers of mountaineering related fatalities and injuries is expected ${ }^{[5]}$. Nevertheless, only few studies have been conducted to determine the risk factors of death in this population ${ }^{[6]}$. Difficulty in determining the exact number of mountaineers in order to estimate the rates of mountaineering-related mortality is the barrier to conduct such studies ${ }^{[7]}$. According to existing reports ${ }^{[1]}$ the rate of fatality among those who participate in mountain hiking in Alpine mountains is about 4 deaths per 100000 hikers per year.

To our knowledge, the reports of fatalities or injuries of mountaineers in high altitude climbing in Himalayas are the only source of information about the risk factors and mechanism of death among mountaineers ${ }^{[8]}$. It has been shown that factors such as falling, barometric pressure, falling temperature and humidity along with increases in solar radiation and wind speed, could lead to the death of mountaineers ${ }^{[9]}$. In addition, climbing at a high difficulty level (relative to the achievements of a given time), high altitude mountaineering, and expeditions to polar regions are the activities with the highest risk of accident for the mountaineers ${ }^{[8]}$.

Sudden cardiac death (SCDs) ${ }^{[1]}$, trauma, high altitude illness, cold injury and avalanche burial ${ }^{[7]}$ have been reported as the common causes of death among high-altitude outdoor enthusiasts ${ }^{[10]}$. Age and sedentary lifestyle are the risk factors for SCDs during mountaineering ${ }^{[1,3]}$. It has been suggested that there is a positive correlation between the age of mountaineers and the rate of injury or death. This finding in addition to the higher rate of SCD among elder mountaineers might be well explained by the lower physical fitness of elders ${ }^{[11]}$. 
Accidents during mountain climbing impose a high burden on both individuals and society. Devising preventive strategies and policies requires a priori knowledge of the causes and mechanisms of such accidents. To our knowledge, there is only scarce data about the possible risk factors of mountaineering deaths in multiple high altitude (above $4000 \mathrm{~m}$ ) mountain ranges worldwide. This study is to determine the causes and mechanisms of death among highaltitude outdoor enthusiasts in Iran.

\section{METHODS AND SUBJECTS}

The study protocol was approved by the Ethics Committee of the Tehran University of Medical Sciences. This study was designed based on previous similar studies ${ }^{[12,13]}$. Briefly, we gathered data in two consecutive steps:

a) Identifying the fatalities due to mountaineering: Any fatalities that occurred during enthusiast highaltitude climbing within borders of Iran from March 2006 to June 2010 were identified. This information was obtained contacting several sources in June to September 2010 (Table 1).

b) Obtaining information about causes and mechanism of death in these cases: Data about the causes and the mechanism of death was collected by contacting the coaches, group leaders, teammates, club members,

Table 1: Sources of information for finding possible catastrophic climbing injuries in Iran

Source

- The National Climbing Federation

- Climbing Committee of each province

- The National Sports Medicine Federation (The National sports insurance database)*

- The Sports Medicine Committee of each province

- News agencies and sports newspapers and magazines

- Well known coaches and mountaineers in different provinces

* Sports insurance is obligatory for any person who wants to practice sport in any clubs in Iran rescue team members, friends and family of dead subjects, using a standardized questionnaire. The first draft of the questionnaire was designed based on the published risk factors from the literature. It was then reviewed and modified by 10 experts, including seven professional coaches and three sports physicians with extensive experience in mountaineering.

The final form comprised of the five following parts:

1. The level of proficiency (skill) of the subject

2. Experience of the subject

3. History of previous accidents related to high altitude activities

4. Detailed information on the mechanism of the injury and the death

5. Quality of the equipment that was used by the subject and the level of medical care they received.

The quality of climbing programs was assessed based on:

1. Whether the climbing program was organized by licensed clubs which are under the supervision of the National Mountaineering and Climbing Federation

2. The quality of equipment that was used by the mountaineers

3. Whether the group leader carried out his/her responsibilities appropriately

To evaluate the potential contribution of the previous medical history to the death of the subjects the following factors were investigated:

1. Past injuries that were related to high altitude activities

2. History of any medical condition

3. History of medical symptoms during the previous high altitude activities

The quality of medical care provided to the victims at the time of accident was evaluated based on:

1. The level of education of the medical team

2. Appropriateness of the first aid care provided to the victim by medical team

Descriptive analysis of the data was performed using SPSS software version 16 (SPSS Inc, Illinois, US).

\section{RESULTS}

A total of 29 deaths during mountaineering, rock climbing, caving and skiing were identified from 
Table 2: Description of the reported fatalities sustained during high-altitude outdoor activities in Iran from 2006 to 2010

\begin{tabular}{|c|c|c|c|c|c|c|c|}
\hline $\begin{array}{c}\text { CASE } \\
\text { No. }\end{array}$ & $\begin{array}{c}\text { Age } \\
\text { (years) }\end{array}$ & $\begin{array}{l}\text { Time of } \\
\text { death }\end{array}$ & $\begin{array}{l}\text { Altitude above } \\
\text { sea level (m) }\end{array}$ & $\begin{array}{l}\text { Mechanism } \\
\text { of accident }\end{array}$ & Cause of death & $\begin{array}{l}\text { Type of } \\
\text { activity }\end{array}$ & $\begin{array}{c}\text { Performance } \\
\text { level }\end{array}$ \\
\hline 1 & 23 & 2009/Win & $<2000$ & Falling & Internal bleeding & Rock climbing & Level2 \\
\hline 2 & 48 & 2006/Spr & $2000-4000$ & & MI & Mountaineering & Level2 \\
\hline 3 & 49 & 2008/Sum & $<2000$ & Falling & Internal bleeding & Rock Climbing & Level 1 \\
\hline 4 & 56 & 2009/Spr & $2000-4000$ & Lightning & Multiple Trauma & Climbing & Level2 \\
\hline 5 & 25 & 2008/Spr & $?$ & Falling & Brain hemorrhage & Mountain Hiking & Level 1 \\
\hline 6 & 53 & 2008/Sum & $2000-4000$ & Falling & Internal bleeding & Climbing & Level3 \\
\hline 7 & 52 & $2008 / \mathrm{Spr}$ & $2000-4000$ & & MI & Mountaineering & Level3 \\
\hline 8 & 39 & 2010/Sum & $2000-4000$ & & MI & Rock climbing & Level3 \\
\hline 9 & 45 & 2008/Aut & $<2000$ & & Hypothermia & Caving & Level3 \\
\hline 10 & 53 & 2009/Spr & $>4000$ & Falling & WS/ Multiple Trauma & Mountaineering & Level3 \\
\hline 11 & 67 & 2008/Win & $2000-4000$ & Falling & WS / Hypothermia & Mountaineering & Level3 \\
\hline 12 & 28 & 2008/Aut & $>4000$ & Falling & Brain hemorrhage & Mountain hiking & Level2 \\
\hline 13 & 24 & 2007/Aut & $<2000$ & Falling & Brain hemorrhage & Rock climbing & Level3 \\
\hline 14 & 46 & 2010/Win & $2000-4000$ & Avalanche & Asphyxiation & Mountaineering & Level3 \\
\hline 15 & 25 & 2010/Win & $2000-4000$ & Avalanche & Asphyxiation & Skiing & Level3 \\
\hline 16 & 38 & 2010/Win & $2000-4000$ & Avalanche & Asphyxiation & Mountaineering & Level2 \\
\hline 17 & 24 & $2009 / \mathrm{Spr}$ & $>4000$ & Falling & Hypothermia & Mountaineering & Level2 \\
\hline 18 & 45 & 2009/Sum & $<2000$ & Falling & WS / Hypothermia & Mountaineering & Level2 \\
\hline 19 & 22 & 2009/Sum & $<2000$ & Falling & WS / Hypothermia & Mountaineering & Level2 \\
\hline 20 & 26 & 2010/Win & $2000-4000$ & Avalanche & Asphyxiation & mountaineering & Level2 \\
\hline 21 & 33 & 2010/Win & $2000-4000$ & Avalanche & Asphyxiation & Mountaineering & Level2 \\
\hline 22 & 44 & 2009/Sum & $2000-4000$ & & MI & Mountaineering & Level2 \\
\hline 23 & 20 & 2008/Win & $2000-4000$ & Avalanche & Internal bleeding & Mountaineering & Level2 \\
\hline 24 & 45 & 2007/Sum & $2000-4000$ & Falling & Brain hemorrhage & Rock Climbing & $?$ \\
\hline 25 & 53 & 2008/Sum & $>4000$ & & HAPE & Mountaineering & Level2 \\
\hline 26 & 39 & $2008 / \mathrm{Spr}$ & $?$ & Falling & Internal bleeding & Mountain Hiking & Level2 \\
\hline 27 & 48 & $2007 / \mathrm{Spr}$ & $<2000$ & Falling & Brain hemorrhage & Rock Climbing & Level2 \\
\hline 28 & 46 & 2009/Sum & $>4000$ & & MI & Mountaineering & $?$ \\
\hline 29 & 27 & 2008/Sum & $>4000$ & & HAPE & Mountaineering & Level3 \\
\hline
\end{tabular}

All but case 17th were male, Spr=spring /sum=summer / aut=autumn /win=winter / MI = myocardial infarction / HAPE: High altitude pulmonary edema / WS: Water Submersion

Level 1: Receiving theoretical education; Level 2: Receiving both theoretical and practical education; Level 3: Receiving official climbing license

March 2006 to June 2010 in Iran (Table 2).

All but one case were males. Deceased subjects had a mean age of 39 years ( $\mathrm{SD}=12.8$, Range: $20-67$ years). Of all cases 14 (48\%) were younger than 40, $14(48 \%)$ were between 40-60 years of age and one (4\%) was older than 60 . We evaluated the functional level of the subjects based on the level of climbing training and the previous climbing experience; we found that only 10 (34\%) subjects were trained to accurately read maps, interpret meteorological phenomena, manage high altitude sickness and use of climbing equipment. Eighteen (62\%) individuals passed the practical courses of mountain climbing, ice climbing, rock climbing, caving, first aid and rescue. All but one of the cases were experienced climbers who had participated in a climbing activity within the year prior to their demise; eleven (38\%) subjects had climbed Damavand summit (the highest summit in the Middle East with $5610 \mathrm{~m}$ height from free seas) and 7 individuals (24\%) had climbed at least one high altitude (height $>5000 \mathrm{~m}$ ) summit abroad in addition to Damavand.

Most of the deaths (83\%) occurred during climbing activities approved by the national climbing federation. Seventeen (59\%) deceased subjects used inadequate or substandard equipments; inappropriate shoes and not using a helmet were the most common. Group leaderships were held responsible by the other members of the climbing groups in $19(66 \%)$ instances of death. However, in most cases the members of the climbing teams were unable to explain how exactly the decisions of group leaders contributed in those 
accidents.

Most deaths occurred in summer (34\%), followed by spring $(27 \%)$, winter $(27 \%)$ and fall $(10 \%)$. Unfavorable weather condition (tempest, snowstorm and rain) was reported in $38 \%$ of climbing attempts, which led to death of the subjects (Table 3 ).

Seven (24\%) deaths occurred at altitudes less than 2000 meters, $14(48 \%)$ at 2000-4000 meters and 6 (21\%) at above 4000 meters (in 2 cases the altitude was unknown). Death occurred in 16 (55\%) subjects during ascent, in $8(27 \%)$ during descent and in $5(17 \%)$ neither during ascent nor descent.

Five subjects $(17 \%)$ had a previous history of mountaineering-related injury, $3(10 \%)$ had history of medical illness, including Alzheimer's dementia, ischemic heart disease and chronic pulmonary disorder, and, 5 (17\%) experienced high altitude illness during the climbing attempt which led to their demise.

In only $7 \%$ of instances $(n=2)$ a physician was accompanying the group. Of 29 subjects 9 (31\%) died immediately after the accident, 9 (31\%) were unconscious but alive when found and the rest (38\%) were conscious before death.

The most common accident leaded to the death of mountaineers was falling (48\%) followed by avalanche (21\%). Asphyxiation (24\%) was the most common cause of death, followed by heart attack (17\%), internal bleeding (17\%), cerebral hemorrhage (17\%), hypothermia $(10 \%)$, and high altitude pulmonary edema $(13 \%)$.

\section{DISCUSSION}

In this study we investigated the mechanism and causes of death among high-altitude outdoor enthusiasts in Iran during a 5 year period. Based on our findings, we identified a number of mechanisms and causes of death in mountaineers. Some of the major factors will be discussed in detail in the following section.

\section{Avalanche:}

Avalanche was the second (21\%) common type of accident among Iranian mountaineers. Five out of 6 avalanche accidents occurred to mountain climbers and
Table 3: Possible contributing factors to fatality among Iranian high altitude outdoor enthusiasts (total of 29 cases)

\begin{tabular}{|lc|}
\hline Possible risk factors & Number of cases \\
\hline Absence of rescue team & 6 \\
Previous illness & 2 \\
Inappropriate equipment & 17 \\
Unfavorable weather & 11 \\
High altitude illness & 5
\end{tabular}

only one to a skier. Boyd et al ${ }^{[14]}$ and Brugger et al ${ }^{[10]}$ reported that the most avalanche-related fatalities occurred among skiers. Lower number of skiers in this study could be due to low popularity of skiing and small number of skiing resorts in Iran. Asphyxia was the major cause of avalanche-related deaths in our study which is in concordance with previous studies ${ }^{[14]}$.

All of the avalanche accidents occurred during January and February in routs that lack avalanche dams; building standard dams at critical locations might be effective in reduction of fatalities from avalanche.

\section{Lightning:}

We found one case of death from lightning (3.5\%); the rate of death due to lightning in mountaineers has been comparably low in the previous reports ${ }^{[15]}$. The victim was a 56 year old male who was climbing in a group when a lightning strike caused him to fall off the edge. To prevent accidents like this, authorities have recommended using a protective helmet and staying belayed in susceptible places ${ }^{[16]}$. In addition, mountaineers should receive training to recognize weather conditions and places high risk for lightning strike, and to take shelter during high risk conditions ${ }^{[16]}$.

\section{Sudden Cardiac Death:}

We found sudden cardiac death (SCD), during high altitude activities, to be the cause of death in 5 cases $(17 \%)$ with a mean age of 46 years $(\mathrm{SD}=4.47)$. Previous studies reported a high rate $(\sim 50 \%)$ of death due to SCD in mountaineers ${ }^{[1]}$. It was also reported that the rate of death due to SCD increases with subject age ${ }^{[1]}$. We searched for a previous history of heart disease among deceased subjects; only one had a positive history of ischemic heart disease (IHD). 
Burtscher et al have reported that SCD is 11 times more prevalent among mountain hikers with a previous history of myocardial infarction. In addition, they reported diabetes mellitus, known coronary artery disease without prior MI, hypercholesterolemia and physical inactivity as other risk factors of SCD during mountain hiking ${ }^{[1]}$.

In this study, in all but one case, who died in an altitude over $4000 \mathrm{~m}$, the sudden cardiac deaths occurred in an altitude between 2000 and $4000 \mathrm{~m}$. We also found that the deaths of all but one occurred during ascent.

\section{Age and gender:}

Of all 29 cases only one was female. All but one of the subjects were below 60 years old and we have observed equal distribution among subjects in $<40$ year and 40-60 age groups. Increased life expectancy in many countries and increased participation of older people in mountaineering might lead to higher rates of death particularly due to cardiac disorders among older mountaineers in the future ${ }^{[11]}$. According to previous studies, approximately $60 \%$ of all deceased mountaineers were older than 40 years and $15 \%$ were older than 60 years ${ }^{[11]}$. As physical fitness declines with age, the risk of morbidity and mortality from mountaineering increases ${ }^{[11]}$. Huey et al ${ }^{[17]}$ showed that the rate of mortality among mountaineers increases with age. They determined that the rate of mortality among the mountaineers older than 60 is three times more than the younger ones ${ }^{[17]}$. However our findings were not in agreement with the mentioned studies, possibly due to lower interest of older people in mountaineering in Iran.

\section{Medical \& Rescue teams:}

In all of our cases, someone familiar with first aid procedures was present in the high-altitude group. Most of those medical service providers, however, did not have advanced medical training and it was difficult for them to diagnose complex diseases. The medical team should be well trained to provide proper medical services in high altitude mountains and to recognize challenging medical situations ${ }^{[18]}$. They should be physiologically well adapted to high altitude environment ${ }^{[17]}$ and also equipped with advanced medical devices such as oxygen and medications for high altitude sickness. Managing the sick or injured mountaineer for several days in cases of delayed transfer to a hospital is another skill the medical service provider of high altitude groups should achieve ${ }^{[18]}$.

\section{Alzheimer's Dementia:}

One of the deceased mountaineers (67 years old) had Alzheimer's dementia. The subject was descending from the summit, when he lost the group and the path. The deceased climber fell into a spring and died because of hypothermia. People with such diseases should not be allowed to participate in an unsupervised mountaineering program.

\section{Water Submersion:}

In this study we reported 4 cases (14\%) of water submersion. Two cases died due to asphyxiation; one of them died because of hypothermia and one because of head trauma.

Three accidents happened when the subjects were trying to cross a river. To prevent such accidents all climbers should be educated properly to find safe points for their river crossing. The climbers should also be well trained for swimming in rapid flows and in water self-rescue. To prevent head trauma the climbers should be advised to wear a helmet while crossing rivers. The medical team should be equipped and trained for management of probable hypothermia.

\section{Limitation:}

Due to the difficulties in determining the exact number of high altitude enthusiasts in a vast area like Iran we could not calculate the rate of high altitude-related fatalities by number of exposure to this kind of activities in this study. Ethical and legal considerations as well as recall bias could also contribute to underreporting of the actual number of cases in this study. The subjective nature of the data (questionnairebased data) and lack of autopsy data in some instances of the identified cases were other limitation of this study. In addition, due to the low number of cases, the recommendations of this study cannot be generalized. Although the questionnaire of the study was developed based on the sports and medical experts' opinions, validation of the questionnaire was not calculated previously. This might be another flaw of the study protocol. 


\section{CONCLUSION}

In conclusion, results of this small descriptive study showed that falling was the most common and avalanche was the second most common mechanism of accident among Iranian mountaineers. Further studies are needed to more accurately identify risk factor and causes of death among high altitude enthusiasts.

\section{ACKNOWLEDGMENTS}

The authors of this manuscript would like to express their gratitude towards the National mountaineering and Climbing Federation and the National Sports Medicine Federation for their kind help in identifying the cases. We would also like to thank Mahmood Nazarian and Jamshid Mohammadi for their contribution.

\section{Conflict of interests: None}

\section{REFERENCES}

1. Burtscher M, Pachinger O, Schocke MF, Ulmer H. Risk factor profile for sudden cardiac death during mountain hiking. Int $J$ Sports Med 2007;28:621-4.

2. Reid WA, Doyle D, Richmond HG, Galbraith SL. Necropsy study of mountaineering accidents in Scotland. J Clin Pathol 1986;39: 1217-20.

3. Ziaee V, Yunesian M, Ahmadinejad Z, et al. Acute Mountain Sickness in Iranian Trekkers Around Mount Damavand (5671m) in Iran. Wilderness Environ Med 2003;14:214-9.

4. Alizadeh R, Ziaee V, Frooghifard LA, et al. The Effect of Path and Beginning Time of Ascending on Incidence of Acute Mountain Sickness around Mount Damavand in Iran (5671 m). Neurol Res Int. 2012;2012:428296.

5. Christensen ED, Lacsina EQ. Mountaineering fatalities on Mount Rainier, Washington, 1977-1997: autopsy and investigative findings. Am J Forensic Med Pathol 1999;20:173-9.

6. Huey RB, Eguskitza X. Limits to human performance: elevated risks on high mountains. J Exp Biol 2001;204:3115-9.

7. Malcolm M. Mountaineering fatalities in Mt Cook National Park. N Z Med J 2001;114:78-80.

8. Weinbruch S, Nordby KC. Fatal accidents among elite mountaineers: A historical perspective from the European Alps. High Alt Med Biol 2010;11:147-51.

9. Windsor JS, Firth PG, Grocott MP, et al. Mountain mortality: a review of deaths that occur during recreational activities in the mountains. Postgraduate Med J 2009;85:316-21.

10. Brugger H, Etter HJ, Zweifel B, et al. The impact of avalanche rescue devices on survival. Resuscitation 2007;75:476-83.

11. Burtscher M. Endurance performance of the elderly mountaineer: requirements, limitations, testing, and training. Wien Klin Wochenschr 2004;116:703-14.

12. Kordi R, Akbarnejad A, Wallace WA. Catastrophic injuries in the Olympic styles of wrestling in Iran. Br J Sports Med 2010;44:16874.

13. Kordi R, Ziaee V, Rostami M, Wallace WA. Indirect Catastrophic Injuries in Olympic Styles of Wrestling in Iran. Sports Health: A Multidisciplinary Approach 2011;3:29-31.

14. Boyd J, Haegeli P, Abu-Laban RB, Shuster M, Butt JC. Patterns of death among avalanche fatalities: a 21-year review. CMAJ 2009; 180:507-12.

15. Mechukaev AM, Mechukaev AA. [Analysis of accidental deaths in mountain tourism and sport according to statistics from the Republic of Kabardino-Balkariia]. Sud Med Ekspert 2006;49:10-4.

16. Zafren K, Durrer B, Herry JP, Brugger H. Lightning injuries: prevention and on-site treatment in mountains and remote areas. Official guidelines of the International Commission for Mountain Emergency Medicine and the Medical Commission of the International Mountaineering and Climbing Federation (ICAR and UIAA MEDCOM). Resuscitation 2005;65:369-72.

17. Huey RB, Salisbury R, Wang JL, Mao M. Effects of age and gender on success and death of mountaineers on Mount Everest. Biol Lett 2007;3:498-500.

18. McIntosh SE, Brillhart A, Dow J, Grissom CK. Search and rescue activity on Denali, 1990 to 2008. Wilderness Environ Med 2010; 21:103-8 